\title{
DECORUM, PRINCIPIO DE RELEVANCIA Y ARGUMENTACIÓN
}

\author{
Cristián Santibáñez Yánez. \\ Universidad Diego Portales, Chile
}

\begin{abstract}
RESUMEN
Primero, el articulo presenta una discusión de las similitudes y diferencias entre el concepto "decorum", fundamental en retórica, y el "principio de relevancia", expuesto por Grice y modificado por Sperber y Wilson, con el objeto de enfatizar la continuidad teórica que existe entre ellos. Posteriormente, se plantea la necesidad de considerar, en una teoría de la argumentación, la "relevancia" desde la perspectiva del "decorum", ya que la adecuación de las emisiones de un hablante no es solo materia de cirscunstancias o expectativas, sino también materia de objetivos y estrategias que un hablante despliega para configurar su caso y convencer.

Palabras clave: Decorum, Relevancia, Falacias, Pragma-dialéctica, Argumentación.

ABSTRACT

First, the paper discusses similarities and differences between the concept "decorum", fundamental in rhetoric, and the "principle of relevance", used by Grice and modified by Sperber and Wilson, to emphasize the theoretical continuity between them. After this, the paper points out the necessity to consider "relevance" from the perspective of "decorum" in argumentation theory, because relevance is not only a matter of circumstances or expectations, but also a matter of objectives and strategies that the speaker uses to build up his case and to convince.
\end{abstract}

Keywords: Decorum, Relevance, Fallacies, Pragma-dialectics, Argumentation.

\section{INTRODUCCIÓN}

Erasmo de Rótterdam le atribuye a Tales de Mileto la siguiente sentencia: "Hablar poco y bueno". ${ }^{1}$ Este tipo de enseñanza, en principio, fue receta para el actuar de los filósofos griegos, pero con el tiempo se ha convertido en sabiduría popular, recomendación social y en un tipo de advertencia moral. Erasmo señala que con esta sentencia Tales de Mileto advertía que el uso de muchas palabras no da prueba de un hombre sabio, porque el sabio no ha de hablar sino cuando la necesidad demanda y las palabras han de ser medidas y correspondientes a la necesidad.

1 Esta sentencia es el apotegma 319 que Erasmo utiliza en su sección titulada "Los siete sabios" de Apotegmas de sabiduría antigua (Erasmo de Rótterdam, 1998: 149). 
A esta enseñanza práctica, y pensándola útil ya no sólo para los sabios, los tratadistas en retórica, helenos y romanos, la sintetizaron en el concepto de decorum, vale decir, la cualidad maxime necessaria de adecuar siempre el hablante su discurso tanto a sus capacidades como a las expectativas del oyente, o audiencia, si ha de procurar conseguir éxito. Por encima de las virtudes técnicas de un discurso, se encuentra la orientación general de que éste debe estar en línea con las afecciones generales de los interesados en la comunicación.

Más de dos mil años después, y en el marco de una teoría racional del intercambio verbal, Grice hace fama con sus 'máximas conversacionales'. Como es bien sabido, a una de ellas Grice (P. Grice, 1975) la denomina 'máxima de relación'. Desde la perspectiva pragmática, esta máxima supone para los hablantes que sus aportaciones al intercambio comunicativo debieran ser relevantes, o, dicho de otra forma, que las informaciones, preguntas u órdenes que un hablante hace a un interlocutor tendrían que ser coherentes con sus expectativas, necesidades o posibilidades, pues de lo contrario el funcionamiento colaborativo de la comunicación no seguiría buen curso. $\mathrm{El}$ aspecto normativo de esta máxima conversacional enuncia que toda aportación en una comunicación sobrepone a lo literalmente expresado la idea de que se expresa por algo o para algo. La consecuencia de este aspecto normativo es que si un hablante quiere ser comprendido, habrá de mostrar en adecuación al oyente lo que intenta e implica.

De modo que un aire de familia hay entre la idea de decorum, uno de los conceptos clave en Cicerón y Quintiliano, ${ }^{2}$ y el concepto de relevancia, muy usado en pragmática, en teoría de la comunicación y por los estudiosos de la argumentación. Y es que, a pesar de las diferencias que imponen el tiempo y el contexto, pareciera ser que une a la perspectiva retórica, germinal en la observación de Tales de Mileto, con el ángulo pragmático de Grice, un sentido general en torno a ambas categorías, a saber, que se debería hablar con adecuación y coherencia según intenciones y circunstancias. ${ }^{3}$ En

${ }^{2}$ En Cicerón las indicaciones más claras se encuentran en De oratore (II 17, III 201-211); en Quintiliano en Institutio oratoria $(11,1,1 ; 11,1,16-28)$. Para una discusión preliminar del concepto en ambos Río Sanz (E. del Río Sanz, 2002: 11-20).

${ }^{3}$ En estricto rigor, no se puede señalar que la de Tales de Mileto sea una sentencia producto de un reflexión sobre el modo retórico del discurso, puesto que, al parecer, en esta área Tales de Mileto no exploró. Sin embargo, sí es razonable tomar esta 'enseñanza' como fuente seminal de lo que después de él, en Aristóteles, Hermágoras de Temnos, Cicerón, Hermógenes de Tarso, Quintiliano, entre muchos otros, será parte de las instrucciones para el proceder retórico para el buen orador. La sentencia de Tales de Mileto, por cierto, también podría tomarse como reflejo de las máximas de cantidad y cualidad de Grice, puesto que mientras la primera sostiene que un hablante debe aportar a una conversación todo aquello que corresponda a toda la verdad relevante a un caso, la segunda señala que el hablante debe emitir la verdad o, mejor, que no debe decir lo que sabe falso o sobre lo cual no tiene prueba o carece de evidencias de que sea verdad, o sea, hablar 'bueno’ en sentido ético. 
términos algo más abstractos, se puede decir que ambas posiciones enfatizan que como no todas las informaciones y expresiones posibles en un diálogo entran en el sentido sensible de lo que se quiere comunicar, el acento en una alocución o enunciado debiera ir en 'relación' con lo que verdaderamente se persigue y puede ser comprendido.

Pero hay una diferencia crucial entre estos dos acercamientos a la idea de hablar en 'adecuación' a intenciones y expectativas en la práctica del discurso. Pues, por ejemplo, mientras en Tales de Mileto se trataría de una indicación al filósofo, a la persona que emite, que aconseja que éste hable en coherencia con su posición e intención de sabio, en Grice se trataría de un principio tácito para todos los involucrados, cuya atención y seguimiento consciente crearía un puente más sólido para que el oyente siga la dirección de lo implicado y complete el sentido. Vista la reflexión del sabio griego desde las estimaciones de la retórica latina clásica, Cicerón aconsejaría tal cuando fuera el caso para que el orador, si quiere manejar el estilo perfecto, logre que un tipo de audiencia acepte lo que pide; ${ }^{4}$ visto desde el ángulo de la lingüística del texto, del análisis del discurso y los análisis de la comprensión, se debiera seguir el principio pragmático de Grice para interpretar por qué el hablante coopera, cuando lo hace, con el oyente para que éste reconstruya el propósito del enunciado o secuencia.

La comparación que se ha expuesto respecto de estos usos alrededor de la idea, incluso intuitiva, de que se debe hablar según las circunstancias, a través de los conceptos de decorum y relevancia -o principio de relevancia-, sólo ha tenido por objeto mostrar el camino que este trabajo seguirá. Con el objeto de postular que en retórica, mediante la ya mentada noción de decorum, se encuentra buena parte de lo que cabe entender por 'hablar en relación', se discutirán aquí algunos de los énfasis de los acercamientos clásicos de ambas categorías y su aplicación en la teoría de la argumentación. Así, se sintetizan primero ciertos alcances del concepto decorum, en lo principal, vinculados a las propuestas de Cicerón y Quintiliano. En segundo término, se revisa la perspectiva de Sperber y Wilson sobre el principio de relevancia; y por último se observa la utilización de la idea general de 'adecuación', ya en términos de decorum, ya en términos de relevancia, en el análisis de la argumentación. En los tres apartados se exponen acentos que perfilan conclusiones, por lo que los aspectos señalados en las mismas sólo enfatizan algunos de los puntos medulares ya instalados en el cuerpo del texto. Cabe señalar que en este trabajo no se hablará de relevancia desde una perspectiva exclusivamente lingüística, sobre la cual hay una bibliografía vastísima, ${ }^{5}$ ni tampoco se profundizará en la noción de "relevancia proposicional" que

\footnotetext{
4 Para Cicerón el 'orador perfecto', o 'estilo oratorio perfecto', a secas no existe, sino que sólo es real aquel estilo que sigue el principio del 'decorum', es decir, aquel estilo oratorio que toma lo que es conveniente para cada momento, para cada circunstancia (Cicerón, 2004: 20-22).

${ }^{5}$ Para una discusión actual y renovada del concepto de relevancia desde esta perspectiva, véase Blakemore (D. Blakemore, 2003: 149-188).
} 
en lógica clásica tiene un tratamiento especial, ${ }^{6}$ sino que se discutirán aquellos aspectos teóricos de la relevancia que han sido incorporados en los debates desarrollados en las teorías de la argumentación contemporáneas. ${ }^{7}$

\section{DECORUM}

Aptum, prosêkon, accommodatum, decens, propium, en griego y latín, son las palabras que se utilizaban indistintamente para referirse al decorum, es decir, al hablar apropiado, adecuado, pertinente, según contexto e involucrados. Se indica a Aristóteles como el primero en discernir sistemáticamente tanto la propia idea de decorum como la noción de relevancia, por cierto no usando estos términos mas el espíritu de los mismos.

Apuntes sobre una 'actuación decorosa' se encuentran en Ética a Nicómaco (1098a) a propósito de vida moral, la búsqueda del bien y la felicidad. Por actuación decorosa entiende y aconseja el Estagirita que en la búsqueda de la felicidad no se debe uno guiar por el afán de la precisión en todo por igual, sino "según la materia subyacente en cada caso y sólo en la medida que es apropiado a la investigación" (Aristóteles, 2002: 60). Lo mismo acontece en Arte Poética de Aristóteles, en donde para él los caracteres en las fábulas deben tender hacia la adecuación "pues es posible que el carácter de una mujer sea valeroso, pero no es adecuado a una mujer ser tan valerosa e inteligente" (Aristóteles, 2003: 93). Sobre la necesidad de que haya equilibrio entre forma y contenido, entre estilo y acción, entre modo e información, Aristóteles en el comienzo del libro III de la Retórica $\left(1404\right.$ a $\left.1405^{\mathrm{a}}\right)$ ensaya sobre la urgencia de mantener las apariencias en la forma de hablar en las artes de la prosa y la poesía. La recomendación general es la adecuación, evitar discordancia, entre los parámetros del género -prosa o poesía- y la creatividad del autor. Ciertas metáforas, ciertos sonidos, determinadas cadencias y ritmos, se imponen al hablar para sentimientos trágicos y cómicos.

Si el decorum es la "armónica concordancia de todos los elementos que componen el discurso" (H. Lausberg, 1976: 258), entonces uno podría decir que lo expuesto en los textos más retóricos de Aristóteles, está más cerca de esta categoría. Pero, si advertimos que desde una perspectiva normativa el principio de relevancia reza como el principio cognitivo que asume que "todo acto de comunicación ostensiva comunica la presunción de su propia relevancia” (D. Sperber y D. Wilson, 1994: 198), ${ }^{8}$ entonces

\footnotetext{
${ }^{6}$ Para una discusión preliminar desde este ángulo, véase Woods (J. Woods, 1994: 82-92).

7 Cabe destacar de inmediato que el tratamiento más completo del concepto desde esta perspectiva se encuentra en Walton (D. Walton, 2003), y en van Eemeren y Grootendorst (van Eemeren and R. Grootendorst, 2004). Una buena introducción en Tindale (Ch. Tindale, 1999, 1994).

${ }^{8}$ Se cataloga aquí la de Sperber y Wilson como una teoría normativa ya que los autores utilizan, a veces explícita otras implícitamente, reglas para el funcionamiento cognitivo, comunicativo y pragmático.
} 
observando los derroteros de las Refutaciones sofísticas el Estagirita advierte sobre 'relevancia' toda vez que el uso falaz de argumentos presupone una normatividad a la hora de calibrar lo permitido en la réplica argumentativa.

Se debe hacer ver que en las Refutaciones se ataca el punto desde el reverso de la relevancia, esto es, desde el argumento que se considera irrelevante y, por tanto, es tomado como falaz. Los paralogismos que se consideran irrelevantes se reúnen bajo el rótulo de la Ignoratio elenchi -ignorancia de la refutación. ${ }^{9}$

De acuerdo a Hamblin (C. Hamblin, 1970: 88), Aristóteles no es del todo claro respecto de cuáles son los factores que hacen que un hablante exponga una conclusión irrelevante, ${ }^{10}$ ya que si se sigue

Otros paralogismos tienen lugar, porque no se ha definido lo que es el silogismo o la refutación, y nacen del olvido de la definición. La refutación es la contradicción de una sola y misma cosa, no de una palabra, sino de una cosa real: y si es de una palabra, no es de una palabra sinónima sino de la misma palabra, que permanece la misma necesariamente conforme a los datos iniciales, sin tomar en cuenta el principio, y permaneciendo la misma relativamente a la misma relación, respecto de la misma cosa, de la misma manera, y en el mismo tiempo... (Aristóteles, 1993: 341).

se obtiene que muchos procedimientos refutatorios, por no decir una gran mayoría, serían de este tipo de falacia, ${ }^{11}$ puesto que dados en el contexto de una disputa real, las definiciones del objeto de la discusión sufren cambios según los datos que en el transcurso se van exponiendo e ingresando en la querella.

Que Aristóteles trasluzca que reflexionar sobre 'adecuación' en el área de los discursos poéticos y retóricos se vincule al decorum, y que la relevancia cabe distinguirla en términos dialécticos y normativos, cuando sabemos que para el Estagirita retórica y dialéctica son las dos caras de una misma moneda, muestra un divorcio innecesario entre las dos categorías.

Sin embargo, y tomando el aire de familia de los términos, ya no visto el tema de la relevancia desde un punto de vista dialéctico -sobre el que se volverá luego-, sino que instalados en una perspectiva retórica, la importancia de la dimensión falaz se debilita, o, dicho de otra forma, cuando con posterioridad a Aristóteles, Cicerón y Quintiliano

\footnotetext{
${ }^{9}$ Para una discusión específica Walton (D. Walton, 1997: 2-5).

10 A la falacia Ignoratio elenchi se la llama también falacia de 'conclusión irrelevante', o 'equivocación de refutación' --Misconception of refutation.

11 De allí que ciertas falacias "ad" -ad hominem, ad misericordiam, ad baculum, ad ignorantiam, ad populum, ad verecundiam- sean consideradas bajo este parámetro, pues desatienden lo que deben refutar. Van Eemeren y Grootendorst (1995: 223) recuerdan que, en el tratamiento estándar de las falacias, a éstas se les llama 'falacias de relevancia'. Willard también las llama así (Ch. Willard, 1997).
} 
hablan de decorum, ser o no falaz estará en función de las circunstancias, siendo el caso que en ocasiones el discurso del hablante debe evitar falacias, y en otras admitir el uso de recursos que dialéctica, o normativamente, se considerarían falaces pues son 'relevantes' para el propósito del discurso -judicial, demostrativo o deliberativo. ${ }^{12}$

Aunque Cicerón no señale directamente que se deba ser falaz en ciertas circunstancias -faltaba más esperar esta inadecuación teórica de Cicerón-, ${ }^{13}$ sí dice en El orador (64), a propósito de la diferencia entre el discurso filosófico y el arte del orador en el foro o senado, que "El estilo filosófico es, en efecto, suave y sombrío, sin frases ni palabras dirigidas al pueblo, sin la atadura del ritmo, sino totalmente libre, en él no hay ira, ni envidia, ni violencia, ni patetismo, ni enrevesamiento; es, en cierto modo, una doncella casta, reservada y sin tacha", connotando que el orador en el senado no escatimará en el uso de recursos violentos o enrevesados. Es más, el asunto lo deja lo suficientemente abierto en El orador (123) cuando sostiene lo siguiente:

Efectivamente, el orador elocuente debe sobre todo poner en práctica la sabia habilidad de adaptarse a las circunstancias y a las personas. Y es que ni siempre, ni ante todos los auditorios, ni contra todos los adversarios, ni en todas las defensas, ni para todos, se debe hablar, pienso, de la misma forma. Será, pues, elocuente aquel que pueda acomodar su discurso a lo que es conveniente en cada caso. Y cuando tenga esto claro, entonces dirá cada cosa como hay que decirla, y no dirá con sequedad lo pingüe, ni con pequeñez lo grande, ni a la inversa, sino que la forma de su discurso estará en paralelo y de acuerdo con el propio contenido.

Asumiendo como línea maestra la idea decorum en El orador, Cicerón lo que nos hace ver es que para ser elocuentes debemos someternos a las orientaciones del concepto, pues decorum es título de un conjunto de procedimientos en la oratoria. Al respecto sostiene en párrafos 69 al 71:

Será, pues, elocuente -al elocuente es, en efecto, al que pretendemos definir, según las indicaciones de Antonio- aquel que en las causas forenses y civiles habla de forma que pruebe, agrade y convenza: probar, en aras de la necesidad; agradar, en aras de la belleza; y convencer, en aras de la victoria; esto último es, en efecto, lo que más importancia de todo tiene para conseguir

\footnotetext{
12 Hasta hoy se observa una discusión abierta en las teorías de la argumentación normativas, como por ejemplo en la pragma-dialéctica, sobre si acaso, por ejemplo, el recurso tu quoque funciona siempre como falacia (T. Govier, 1981; van Eemeren and P. Houtlosser, 2003).

13 Pero tampoco es difícil encontrar en la práctica discursiva propia de Cicerón, como en los Discursos cesarianos, lo que hoy serían evidentes falacias. Para defender a Quinto Ligario, casi al comienzo de su discurso ante el César, en el párrafo 2, Cicerón no escatima en usar tu quoque para atacar a Quinto Tuberón, el acusador. Para el examen de falacias ad hominem, como tu quoque, en relación con el concepto de relevancia Brinton (A. Brinton, 1995: 213-222), van Eemeren y Grootendorst (van Eemeren and Grootendorst, 1995: 223-228).
} 
la victoria. Pero a cada una de estas funciones del orador le corresponde un tipo de estilo: preciso a la hora de probar; mediano, a la hora de deleitar; vehemente, a la hora de convencer, que es donde reside toda la fuerza del orador. Así pues, el orador que sepa regular y, por así decir, ensamblar esta triple variedad, deberá tener gran discernimiento y extraordinarias cualidades; deberá, en efecto, discernir qué conviene en cada caso y así hablar en cada caso según le exija la causa.

Pero la base de la elocuencia, como de las demás cosas, es el buen sentido. Efectivamente, de la misma forma que en la vida, también en los discursos lo más difícil es ver qué es lo que conviene. Prépon llaman los griegos a esto; nosotros lo podemos llamar más bien "lo conveniente"; sobre ello se dan muchos preceptos excelentes y el tema merece ser conocido...

El orador debe mirar lo conveniente no sólo en las ideas, sino también en las palabras. $Y$ es que las personas con diferentes circunstancias, con diferente rango, con diferente prestigio personal, con diferente edad, y los diferentes lugares, momentos y oyentes no deben ser tratados con el mismo tipo de palabras o ideas; hay que tener en cuenta en todas las partes del discurso, de la misma forma que en las de la vida, qué es lo conveniente; y lo conveniente depende del tema que se trate y de las personas, tanto las que hablan como las que escuchan.

Cicerón dice que este ideal es reconocido por todos y digno de estudio, que sería difícil ir en contra de él porque es evidente y de enorme utilidad. Aquí cabría recordar que para Grice la relevancia es, como lo señala Montolío (E. Montolío, 1998: 94), simplemente la conveniencia de que el hablante se adapte de un modo pertinente al tema de la conversación. Esta explicación es pariente cercana de la explicación de la noción de decorum. Se ha tomado más arriba la noción de Sperber y Wilson sobre relevancia pues frente a ella las diferencias con la noción de decorum se alzan con propiedad, aun cuando persisten elementos en común. Por lo pronto, apuntar una diferencia capital. Si bien para Cicerón se puede construir, enseñar y practicar un conjunto de reglas retóricas para obtener elocuencia, la aplicación de tales reglas depende del criterio superior del decorum, el que se adquiere, no obstante, a través de la experiencia, por lo que es, por tanto, un elemento, como indica del Río Sanz, "inartificialis, esto es, fuera del ars, de la téchne" (E. del Río Sanz, 2002: 17); a diferencia de Sperber y Wilson para quienes "el principio de relevancia" es un mecanismo instalado en la maquinaria mental en tanto equipaje genético. Dicho de otra forma, para Cicerón el decorum es una cualidad que se obtiene, y para los teóricos de la comunicación del siglo XX la relevancia es una función, selectiva, que crece de forma natural y se aplica sin excepciones cuando nos comunicamos.

Quintiliano, por su parte, se da a la tarea de entregar detalles de cómo ser adecuado al comienzo del libro XI de su Institutio oratoria. Por ejemplo, evitar a toda costa la autoalabanza, pues despierta no sólo el aburrimiento sino también la animadversión. 
Sobre este último consejo, Quintiliano señala que se trata de lograr un equilibrio entre no presumir demasiado de las propias cualidades y la necesidad de mostrar a veces abiertamente confianza en ellas. Lo mismo aconsejará respecto de usar en determinadas circunstancias el recurso de la autoridad (prestigio, experiencia, sabiduría, trayectoria), la combinación de estilos en una elocutio, el ornatus, numerus, etc., pues el orador debe hablar apte, en accommodatus. El decorum en Quintiliano está también vinculado a la intellectio, ya que es un parámetro guía en la selección de contenidos para la elocutio, es decir, funciona desde la inuentio.

También en Quintiliano hay una preocupación por la relación entre decorum y el deber del orador, la obligación ética de éste de hacer lo que se debe hacer antes de que se consuma por el objetivo de lograr efectividad. El ejemplo es la manera en que Sócrates se defendió, salvando su dignidad y siendo coherente, decoroso, consigo mismo antes que claudicar frente a los jueces. El ethos del orador, en virtud de esta consideración del decorum, está sobre la necesidad de persuadir.

Aspecto este último que nos hace volver al tópico de usar recursos falaces en un discurso y así perder la relevancia -Aristóteles-, o perder el decorum -Cicerón, De Officiis. Pues es el caso de que en De Officiis Cicerón entrega una versión del decorum vinculada directamente al deber -ideal- de virtud; por tanto enfatiza la sujeción del comportamiento discursivo a la templanza, la modestia y la verecundia, es decir, al respeto hacia los demás, actitud que siempre se refleja más como proceso interno, mental, que como asunto de la realidad. A través del decorum se unen entonces lo ético y lo retórico, y del siguiente modo como lo explica Cicerón:

Hemos de hablar ahora de la única parte de la honestidad que nos queda, en la que podemos señalar la discreción y, a modo de ornato de la vida, la templanza y la ponderación, así como todo dominio de las perturbaciones del espíritu y la mesura en todas las cosas. En ese aspecto se encierra lo que en latín podemos llamar decorum, lo decoroso o conveniente, que es lo que en

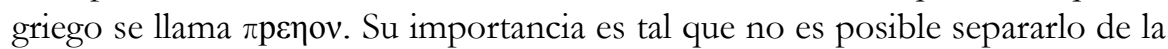
honestidad. -Porque lo que es decoroso es honesto y lo que es honesto es decoroso. En cuanto a saber qué clase de diferencia hay entre lo honesto y lo decoroso, es esta una cuestión más fácil de entender que de explicar. Pues todo lo que es decoroso se manifiesta precisamente así, siendo así que previamente es honesto. Por eso qué es lo que es decoroso no solamente se manifiesta en esta parte de la honestidad de que hemos de hablar aquí, sino también en las tres precedentes. Porque servirse de la razón y del lenguaje con prudencia, hacer con reflexión lo que uno hace, ver qué es lo que hay de verdadero en toda cosa y defenderlo, eso es decoroso; por el contrario, ser engañado, equivocarse, ser inducido a error, errar es tan indecoroso como delirar o enloquecer; y todas las acciones justas son decorosas, mientras que las injustas, muy al contrario, lo mismo que son vergonzosas, son indecorosas... Por ello, ese decoro de que estoy hablando atañe sin duda al 
campo total de la honestidad, y de tal manera está relacionado con ella que se discierne, no en virtud de algún razonamiento oculto, sino a simple vista. Hay, en efecto, algo que es decoroso y que puede verse en toda virtud; y eso puede distinguirse de la virtud más por obra del pensamiento que en la realidad. De la misma manera que no es posible separar la gracia y la belleza corporales de la salud, de la misma manera ese decoro de que hablamos está totalmente mezclado con la virtud, si bien se diferencia de ella por obra del pensamiento y la reflexión (Cicerón, 1978, párrafos 93-95).

\section{Principio de RELEVANCIA}

Sostuvo Grice: "Make your conversational contribution such as is required, at the stage at which it occurs, by the accepted purpose or direction of the talk exchange in which you are engaged" (P. Grice, 1975: 66). Y lo sostuvo, como es bien sabido, para explicar su tercera máxima conversacional en el marco del principio de cooperación que subyace a la comunicación cotidiana entre humanos.

Así expuesta, la relevancia es decorum. Como sostiene Grice (P. Grice, 1998: 107), se trata de que uno "haga contribuciones pertinentes" a lo que se habla con un interlocutor. Cicerón diría que si no se hacen las contribuciones en este sentido, perdemos el decoro. Quintiliano también. Y, desde una perspectiva argumentativa, Aristóteles diría que si perdemos el foco del alegato y argumentamos sin atender a lo específicamente en disputa, ignoramos lo que está bajo refutación y, así, somos irrelevantes, falaces.

Pero el término contemporáneo de relevancia tampoco tiene sola una versión. Se debe a Sperber y Wilson (D. Sperber y D. Wilson, 1994) una modificación sustancial del concepto, y también a la teoría completa y modelo inicial de Grice. Uno de los aspectos centrales de la propuesta de los autores, acorde con su perspectiva cognitivista, y resultado prototípico del impacto de la epistemología americana muy cercana a la teoría de W. O. Quine, es asumir el término como una manifestación del funcionamiento de la estructura mental de hablantes y oyentes. Pero esta propuesta tampoco está exenta de alcances retóricos. Como la expusimos más arriba, la definición general del principio asume un efecto, un logro, sobre el oyente, audiencia o destinatario respecto del enunciado o estímulo. Frente a posibles preguntas críticas en torno a tal definición, los autores en el apartado 7 del capítulo 3 entregan respuestas que podrían leerse en este sentido retórico, en el entendido de que la retórica es el estudio de las formas en que se buscan logros en un destinatario. En el capítulo indicado, Sperber y Wilson señalan:

\section{¿Hasta qué punto es fiable la presunción de relevancia?}

Como todos sabemos, el mundo está lleno de pelmazos. El principio de relevancia no dice que los emisores produzcan necesariamente estímulos óptimamente relevantes, dice que necesariamente quieren que el destinatario 
crea que lo hacen. También las personas más pesadas quieren manifiestamente que sus oyentes crean que merece la pena escucharlas.

La presunción de relevancia comunicada por un enunciado no tiene por qué aceptarse como verdadera. Puede que el emisor no consiga alcanzar la relevancia, o puede que el destinatario dude de que el emisor sea capaz de ser relevante. Sin embargo, de la presunción de relevancia se desprende la presunción, más fiable, de que se ha intentado, si es que no se ha conseguido, ser relevante. Un emisor que no consiga hacer manifiesto para sus oyentes que está siendo óptimamente relevante puede, sin embargo, conseguir hacer manifiesto que está intentando ser óptimamente relevante. No obstante, hay que considerar que la comunicación ostensiva comunica algo más que una mera presunción de intento de relevancia. Puede que el destinatario desee creer que el emisor ha intentado ser relevante con todas sus fuerzas, pero si, además, cree que no lo ha conseguido en absoluto, no le prestará atención. Así que, por mucho que dude de sí mismo, un emisor debe intentar hacer manifiesto para el destinatario que su estímulo ostensivo es suficientemente relevante. (D. Sperber y D. Wilson, 1994: 199).

Queda absolutamente claro que la perspectiva se concibe como una caracterización de lo mental, lo interno, a la hora de asumir intenciones, presunciones y comunicación, pues la relevancia existe incluso antes de que se hable; que la presunción de intención de relevancia parte del supuesto de la importancia informativa, evocado este aspecto en la idea de que el envío de estímulos en el marco de una comunicación ostensiva busca, al menos, hacer creer que el emisor persigue la relevancia. Mientras en la propuesta retórica esto se consigue con el obrar en el discurso, en la propuesta de Sperber y Wilson esto viene en la naturaleza misma de comunicar ostensivamente, y dado que siempre procedemos así, con o sin lenguaje, entonces somos por naturaleza retóricos, en tanto en cuanto tenemos la relevancia como mecanismo base para dirigir respuestas, seleccionar contextos de esas repuestas, estimular determinada información enciclopédica para la comprensión de la comunicación ostensiva, y para desechar interpretaciones. El mensaje es que ya hemos integrado, por selección genética, este comportamiento comunicativo.

El encuadre general para esta convicción es que, como lo ha resumido bien Montolío a propósito del vínculo entre relevancia y el análisis de los marcadores del discurso (E. Montolío, 1998: 94-98), la mente se concibe como una estructura eficaz en el tratamiento de la información ya que está orientada hacia la búsqueda de relevancia, y está orientada de esta forma porque, dada la enorme cantidad de estímulos en el ambiente para nuestros procesos de percepción, seleccionamos en función de lo que destaca en informatividad a bajo costo energético y amplia cobertura de sus consecuencias. Siempre maximizamos relevancia, seleccionando y construyendo el contexto de interpretación de una comunicación más adecuado para comprender, sobre todo, lo que se nos implica, a través de protocolos deductivos. 
Por supuesto, no se trata de confundir todos los planos o niveles de análisis entre los acentos de un trabajo en retórica, donde parte del trabajo es distinguir figuras como estrategias, con los énfasis comunicativo-pragmáticos para descifrar implicaturas, desambiguación y asignación de referencia, por ejemplo, ${ }^{14}$ sino de atender al hecho general que entre decorum y relevancia existe una continuidad teórica importante, a saber, la distinción de una necesidad o función de comunicarse vía lo conveniente para cada caso, circunstancias, personas, información y contextos involucrados. La necesidad o función podría ser asumida como mandato genético, exigencia discursiva, expectativa social, normatividad lingüística, advertencia moral o consejo filosófico, o todos a la vez.

Pero hay punto metodológico y analítico que, a nuestro juicio, desequilibra la balanza hacia la contundencia del estudio retórico de lo conveniente, relevante o decoroso. Pues, mientras en Sperber y Wilson siempre se dan ejemplos triviales de enunciados o cadena de enunciados de corto alcance en discursos descriptivos o evaluativos para mostrar sus análisis, en retórica siempre se ha asumido el riesgo ejemplificando con discursos completos, distinguiendo figuras específicas sin perder la totalidad. Y sucede así porque los pragmáticos analizan intercambios informativos simples y directos, más que disputas, controversias o argumentaciones.

\section{ARguMENTACIÓN}

Señalamos que Aristóteles considera que la relevancia, o pérdida de ella, se debe medir normativamente. Pero no es sólo él quien así lo conceptualiza. También tratan a la relevancia de este modo van Eemeren y Grootendorst (van Eemeren and R. Grootendorst, 1992, 2004), Johnson (R. Johnson, 2000), y Walton (D. Walton, 1997), entre otros muchos de los teóricos contemporáneos de la argumentación. En realidad, la perspectiva normativa es la que domina la concepción de relevancia en los análisis de la argumentación, ${ }^{15}$ aun cuando exista, como van Eemeren y Grootendorst indican,

14 Por lo demás, la crítica que hacen los propios Sperber y Wilson (D. Sperber y D. Wilson, 1998: 158) a Grice sobre su modelo remite directamente a la consideración de elementos pragmáticos bajo la luz de una teoría retórica: Así, mientras Grice subestimó el alcance de las máximas en el caso de decir frente a implicitar, parece haberlo sobreestimado en el caso de la interpretación figurativa. Se impone, pues, un nuevo tipo de mecanismo interpretativo, además del semántico y pragmático ya disponibles, que pueda responder a la ironía, la metáfora y la interpretación figurativa en general. Se ha hecho un progreso considerable, sobre todo gracias a Grice, al liberar a la semántica de una serie de problemas que serían mejor tratados en una teoría mejorada de pragmática; ahora parece que si la pragmática va a progresar más, habrá de ser liberada a su vez de una serie de problemas que no pueden tratarse desde puntos de vista puramente gramaticales o lógicos y que requieren un tratamiento separado en una teoría de la retórica.

15 Pareciera ser que la preocupación por la relevancia no existe en la teoría de los topoi o teoría de los bloques semánticos de la argumentación de Ducrot y Anscombre (O. Ducrot y J-C. 
al menos dos tendencias sobre el concepto: una descriptiva e interpretativa, y otra propiamente normativa y evaluativa (van Eemeren and R. Grootendorst, 2004: 71). La primera se pregunta por: cuándo un acto de habla $\mathrm{A}$ es visto como una reacción apropiada al acto de habla $\mathrm{B}$, o cómo los participantes en una conversación determinan cuándo una segunda parte de lo que se dijo más temprano es relevante; el segundo ángulo se pregunta por: cuándo un ataque personal, la apelación a la autoridad, a la misericordia, o amenaza, para obtener la aceptación de un punto de vista, son rechazados por irrelevantes, o cuáles son los criterios que determinan si ciertos actos de habla pueden ser juzgados como relevantes (va Eemeren and R. Grootendorst, 2004: 71). En ambos ángulos, no obstante, la relevancia se observa como un fenómeno específico dentro del problema mayor de mantener o perder la coherencia en un discurso o texto producido por uno o más hablantes.

Para la pragma-dialéctica, es decir, desde un punto de vista evaluativo conforme a reglas que guían la resolución crítica de una diferencia de opinión, un análisis adecuado de la relevancia consiste en determinar cómo un complejo de actos de habla funciona en su dominio contextual, componente verbal y adecuación relacional (van Eemeren and R. Grootendorst, 2004: 83); para Johnson la relevancia es tanto un fenómeno vinculado a la propiedad de las proposiciones encadenas en un argumento, aunque aquellas estén implícitas, como a las propiedades pragmáticas del mismo y a las relaciones dialécticas y contextuales de un intercambio argumentativo, siendo por tanto la relevancia una cuestión de grados (R. Johnson, 2000: 137). Walton, por su parte, concibe la relevancia tanto como un parámetro formal -en virtud del uso de una secuencia (in)correcta de argumentos y proposiciones propiciadas por tipos de esquemas argumentativos-, como una categoría que indica calidad dialéctica del argumento en función del tipo de diálogo en el que se lleva a cabo. ${ }^{16}$

Anscombre, 1994); y que tampoco existe, tratada en estos términos de normatividad, en Perelman y Olbrechts-Tyteca (Perelman and Olbrechts-Tyteca, 2000). Lo que sí existe en estos últimos dos autores es la indicación de que la pérdida de relevancia, a través por ejemplo del recurso de la broma o diversión en una disputa, señalada por los autores cuando examinan los riesgos de la figura de la amplitud (Perelman and Olbrechts-Tyteca, 2000: 484-485), complota contra un hablante haciéndole perder el punto y configurando su actuación argumentativa como débil. Los autores belgas señalan que cuando un hablante se da cuenta de que no puede usar el recurso de la diversión en un argumento se debe a que, citando a Quintiliano, el argumento es contrario al buen gusto, es peligroso, o está simplemente prohibido, y usarlo sería perder el decorum. Para evitar esto, Perelman y Olbrechts-Tyteca indican que una fórmula de continencia es el uso del recurso de 'reticencia' (Perelman and Olbrechts-Tyteca, 2000: 488) y el ejemplo que dan proviene de Rhetorica ad Herennium -IV, 37-.

16 Sostiene al respecto Walton: "This analysis shows how dialectical relevance of an argument should be defined by the use of the argument in one of these six types of dialogue -persuasion dialogue, inquiry, negotiation, deliberation, information-seeking dialogue, and eristic dialogue... Whether an argument is dialectically relevant or not, in a given case, can be judged using these six conversational frameworks as normative models." (D. Walton, 1997: 168-169), 
Como han indicado van Eemeren y Grootendorst (van Eemeren and $\mathrm{R}$. Grootendorst, 2004), en general el análisis de la relevancia se subordina al problema de la coherencia en un discurso o texto argumentativo. A nivel local el análisis de la relevancia, que se da por defecto o falta, se suscita cuando se observa o acusa una inadecuación entre una emisión y su reacción; y a nivel global, cuando un hablante enuncia un discurso no atingente al tema o contexto. Nótese que el primer nivel se podría vincular más con lo que Grice entiende por relevancia, y el segundo con lo que se entiende clásicamente por decorum.

La relevancia se analiza solo cuando hay error desde la perspectiva evaluativa. Así, se asume funcionando y en uso en la argumentación, en un sentido cercano al de Sperber y Wilson, esto es, como proceso natural, cuando una polémica se lleva a cabo sin ignoratio elenchi o en accommodatum a la situación, tema o circunstancias, de lo contrario son los propios usuarios del lenguaje ordinario los que indican, en mención, que alguien ha perdido la pertinencia en frases tales como: "Pero lo que dices no es relevante para lo que estamos discutiendo". ${ }^{17}$

También puede darse el caso de que esta última reacción típica responda a una táctica, en función de un riesgo que una de las partes conscientemente quiera correr en una parte de su discurso argumentativo para lograr un efecto final de convencimiento o persuasión. Se daría, entonces, un uso estratégico de la (no)relevancia, en el que se posterga, pospone o se pone entre paréntesis la relevancia local. Schopenhauer llamaría a esto una estratagema. Incluso se podría tomar su estratagema 4 como una explicación de este hecho (Schopenhauer, 2003: 37). A propósito de lo mismo, Aristóteles en Tópicos, Libro VIII, cap. 1., advierte sobre lo conveniente que es ordenar, presentar, disponer, oscuramente si es necesario, las partes del silogismo al momento de preguntar, rebatir o proponer. De modo que el entendimiento y aplicación del criterio de relevancia, si es una cuestión de grados, no depende principalmente de su relación con el contexto, sino, más bien, de la disposición y objetivos que un hablante tiene para con su discurso argumentativo. Por cierto, las más de las veces un buen argumentador hará coincidir la formulación de sus

y luego: "Relevance of an argument is determined at the local level by the sequence of questions and replies (the profile of dialogue), in relation to how the sequence matches the proper normative profile determined by the argumentation scheme and the appropriate critical questions. But relevance is determined at the global level by the type of dialogue the argument is supposed to be part of, and by its contribution, at a given stage of this dialogue (D. Walton, 1997: 169). Walton señala que 'apelar a la misericordia' es siempre falaz desde la perspectiva de van Eemeren y Grootendorst, esto es, en el marco del tipo de diálogo 'discusión crítica', mientras que el mismo recurso usado en una deliberación puede justificarse como relevante.

${ }^{17}$ Johnson (R. Johnson, 1995: 117) recuerda que el uso latino de non sequitur cuando se observa el uso de una premisa irrelevante para una conclusión, añadiendo que, en inglés, se marca con: "That doesn't follow". 
argumentos con la exposición de reacciones relevantes en contenido y forma en un continuo argumentativo.

Desde una perspectiva normativa, el uso estratégico de manipulación de la relevancia sería siempre una fórmula falaz, descarrilada (van Eemeren and P. Houtlosser, 1999; 2002a, 202b, 2002c). Pero se podría decir también que en línea con la idea de decorum como coherencia interna del hablante (el ejemplo es el de Sócrates), se asistiría a una clase de atención hacia la misma si el tipo humano constantemente en sus discusiones actúa de un modo estratégico perdiendo relevancia en una parte del discurso para obrar con coherencia global con el punto de vista general que sostiene. Por otra parte, en la argumentación jurídica existe el silogismo denominado 'sorites', el que se caracteriza por ser una inferencia obtenida a partir de una premisa localmente no vinculada con la conclusión, por tanto aparentemente irrelevante en primera instancia en su aspecto formal, pero que reconstruidos todos sus pasos silogísticos se obtiene la conclusión aludida. Por eso, en función de procedimientos argumentativos, en los que se combinan consideraciones dialécticas y circunstanciales, la relevancia se debería medir también retóricamente. Incluso, en ciertos contextos sociales la audiencia (la académica, por ejemplo) espera, y presiona por, ciertos 'ritos de paso' en los que un hablante u oyente o debe emitir de forma atenuada apelaciones a la misericordia o a la autoridad, o debe aceptar otros movimientos considerados a priori irrelevantes, y por tanto falaces, en orden a seguir la controversia en su contenido medular o importante. En este sentido, Johnson (R. Johnson, 2000: 204) se equivoca cuando sostiene que la relevancia es una propiedad eminentemente pragmática. La relevancia es también una propiedad retórica. ${ }^{18}$

En esta misma vena retórica, podría darse el hecho de que la acusación de irrelevancia, evocada en frases como "Pero lo que dices no es relevante para lo que estamos discutiendo", también fuera una maniobra del receptor para confundir al hablante, ganar tiempo, cambiar énfasis, sugerir el ingreso de otros elementos en la discusión. De allí, por lo mismo, que van Eemeren y Grootendorst no opten por la versión descriptiva e interpretativa de la relevancia en el análisis de la argumentación, sino que, al contrario, opten por reglas que aseguran la relevancia desde una perspectiva normativa. No obstante, esta elección de van Eemeren y Grootendorst se ha visto indirectamente afectada cuando asumen que la aplicación y seguimiento de reglas es de difícil consecución, por la complejidad técnica de las mismas y la imposición de las circunstancias de la argumentación en vivo. Por tal motivo, han reemplazado, en vistas de la funcionalidad del modelo para los usuarios, la búsqueda de la aplicación de las reglas específicas de actos de habla en cada etapa de una

\footnotetext{
18 Incluso en fonética existe el concepto como 'relevancia abstractiva' (abstraktive Relevanz), con el que se alude al hecho de que cuando oímos extraemos de la cadena hablada lo que es relevante diacríticamente.
} 
discusión crítica, por la recomendación de uso de preceptos, o comandos, para la buena conducta argumentativa en una discusión crítica. ${ }^{19}$

\section{CONCLUSIONES}

El entronque entre la práctica argumentativa, la reflexividad de los usuarios, que denuncian metadialógicamente cuándo su contrincante supuestamente emite un acto de habla irrelevante, y la normatividad asociada a la racionalidad procedimental ideal para una resolución crítica en función de lo decoroso o relevante, es una relación de parentesco que aún no reconoce todas las ramificaciones de su linaje. ${ }^{20}$ Comprender la relevancia como decorum, pasar de la acentuación de la informatividad, de la trivialidad de los ejemplos de Sperber y Wilson, a los contornos que de su uso en la práctica argumentativa y retórica se dan, ayudaría a sopesar los distintos niveles que la categoría tiene en los argumentos y en los tipos humanos que la hacen funcionar.

\section{REFERENCIAS BIBLIOGRÁFICAS}

ARISTOTLE, Posterior Analytics. Topica, edited and translated by Hugh Tredennick, Cambridge, Harvard, reprinted 1997.

ARIstotLe, The Art of Rhetoric, translation by John Henry Freese, Cambridge, Harvard, reprinted 2000.

ARISTÓTELES, Refutaciones Sofísticas, edición Francisco Larroyo, México, Porrúa, 1993.

ARISTÓTELES, Ética a Nicómaco, traducción de José Luis Calvo, Madrid, Alianza, 2002.

Aristóteles, Arte Poética, edición bilingüe de Aníbal González, en Aristóteles y Horacio. Artes Poéticas, Madrid, Visor, 2003, pp. 46-149.

Blakemore, D., Relevance and Linguistic Meaning: The Semantics and Pragmatics of Discourse Markers, Cambridge, Cambridge University Press, 2003.

Brinton, A. "The Ad Hominem", en H. Hansen and C. Pinto (eds.), Fallacies. Classical and Contemporary Readings, Pennsylvania, The Pennsylvania State University, 1995, pp. 213-222.

Castillo, C. "La cristalización del pensamiento ciceroniano en el De Officiis de San Ambrosio", Anuario Filosófico, 34 (2001), pp. 297-322.

CICERÓn, El Orador, traducción y edición de Eustaquio Sánchez Salor, Madrid, Alianza, reimpresión 2004.

CiCERÓn, Sobre el orador, traducción de J. Iso Echegoyen, Madrid, Gredos, 2002.

CICERÓN, Retórica a Herenio, traducción y edición de Juan Francisco Alcina, Barcelona, Bosch, 1991.

${ }^{19}$ Este cambio de énfasis se encuentra en van Eemeren y Grootendorst (van Eemeren and Grootendorst, 2004: 187-196).

${ }^{20}$ Una mención de estas relaciones se encuentra en Willard (Ch. Willard, 1995: 145-158). 
CiCERÓn, Discursos cesarianos, traducción de José Miguel Baños, Madrid, Alianza, 1991.

CiCerón, Los deberes, traducción de Miguel de Valbuena, Barcelona, Vosgos, 1978.

Ducrot, O. y J-C. Anscombre, La argumentación en la lengua, Madrid, Gredos, 1994.

EEMEREN, F. H. van and R. Grootendorst, Argumentation, Communication, and Fallacies. A Pragma-Dialectical perspective, Hillsdale, Erlbaum, 1992.

Eemeren, F. H. van and R. Grootendorst, A Systematic Theory of Argumentation. The pragma-dialectical approach, Cambridge, Cambridge University Press, 2004.

Eemeren, F. H. van and R. Grootendorst, "The Pragma-dialectical approach to Fallacies", en H. Hansen, H. and C. Pinto (eds.), Fallacies. Classical and Contemporary Readings, Pennsylvania, The Pennsylvania State University, 1995, pp. 130-144.

Eemeren, F. H. van and R. Grootendorst, "Argumentum ad hominem: A Pragmadialectical Case in Point", en H. Hansen and C. Pinto (eds.), Fallacies. Classical and Contemporary Readings, Pennsylvania, The Pennsylvania State University, 1995, pp. 223-228.

EEMEREN, F. H. van and P. Houtlosser, "Strategic maneuvering in argumentative discourse", Discourse Studies, 1 (1995), pp. 479-497.

Eemeren, F. H. van and P. Houtlosser, "Strategic Maneuvering with the burden of proof", en (Ed.) F. van Eemeren (Ed.), Advances in Pragma-Dialectics, Amsterdam, Sic Sat, 2002a, pp. 13-28.

EEMEREN, F. H. van and P. Houtlosser, "Fallacies as derailments of strategic maneuvering: The Argumentum ad Verecundiam, A case in point", en F. van Eemeren, A. Blair, Ch. Willard and F. Henkemans (eds.), Proceedings of The Fifth Conference of The International Society for The Study of Argumentation, Amsterdam, Sic Sat, 2002b, pp. 289-292.

Eemeren, F. H. van and P. Houtlosser, "Strategic maneuvering: Maintaining a delicate balance", en F. van Eemeren and P. Houtlosser (eds.), Dialectic and Rhetoric: The warp and Woof of Argumentation Analysis, Dordrecht, Kluwer Academic Publishers, 2002c, pp. 131-159.

Eemeren, F. H. van and P. Houtlosser, "More about fallacies as derailments of strategic maneuvering: The case of tu quoque", Proceedings of the 25 Conference at the University of Windsor, Ontario, Canada, 2003.

ERASMO de Rótterdam, Apotegmas de sabiduría antigua, edición de Miguel Morey, Barcelona, Edhasa, 1998.

Govier, T., "Worries about tu quoque as a fallacy", Informal Logic Newsletter, 3 (1981), pp. 2-4.

GRICE, H. P., "Logic and conversation", en P. Cole and J. Morgan (eds.), Syntax and Semantics. Volume 3: Speech Acts, New York, Academic Press, 1975, pp. 41-58. 
GrICE, H. P., "Presuposición e implicatura conversacional", en M. Julio y R. Muñoz (comp.), Textos clásicos de pragmática, Madrid, Arco Libros, 1998, pp. 105-124.

Hamblin, C. L., Fallacies, London, Methuen, 1970.

Horacio, Epístola a los pisones, edición bilingüe de Aníbal González, en Aristóteles y Horacio. Artes Poéticas, Madrid, Visor, 2003, pp. 150-185.

JOHnson, R., "The Blaze of her Splendor: Suggestions about Revitalizing Fallacy Theory", en H. Hansen and R. Pinto (eds.), Fallacies. Classical and Contemporary Readings, Pennsylvania, The Pennsylvania State University Press, 1995, pp. 107119.

Johnson, R., Manifest Rationality. A Pragmatic Theory of Argument, New Jersey, Lawrence Erlbaum Associates, Inc., 2000.

Lausberg, H., Manual de retórica literaria. Fundamentos de una ciencia de la literatura, Madrid, Gredos, 1976.

MonTOLÍO, E., "La teoría de la relevancia y el estudio de los marcadores discursivos", en M. Martín y E. Montolío (coords.), Los marcadores del discurso. Teoría y análisis, Madrid, Arco Libros, 1998, pp. 93-119.

Perelman, Ch. and L. Olbrechts-Tyteca, The new rhetoric. A Treatise on Argumentation, Notre Dame, University of Notre Dame Press, 2000.

QUintilian, The Orator's Education. Books 11-12, edited and Translated by D. Russell, Cambridge, Harvard, 2001.

Río SANZ, E. del, "Quintiliano y su idea del Decorum: Estilo, Ética y Retórica”, Berceo, 143 (2002), pp. 11-20.

SANTIBÁÑEZ, C., "Retórica y argumentación en la política de sentencias populares", Praxis: Revista de Psicología y Ciencias Humanas, 9 (2006), pp. 183-196.

SCHOPENHAUER, A., El arte de tener razón expuesto en 38 estratagemas, traducción de D. Garzón, Madrid, Edaf, 2003.

SPERBER, D. y D. Wilson, La relevancia. Comunicación y procesos cognitivos, Madrid, Visor, 1994.

Tindale, Ch., "Contextual Relevance in Argumentation", en R. Johnson and A. Blair (eds.), New Essays in Informal Logic, Windsor, 1994, pp. 67-81.

Tindale, Ch., Acts of Arguing. A Rhetorical Model of Argument, New York, State University of New York Press, 1999.

Walton, D., Appeal to pity. Argumentum ad misericordiam, New York, State University of New York, 1997.

WALTON, D., Relevance in Argumentation, New York, LEA, Inc., 2003.

WILSON. D. y D. Sperber, "Sobre la teoría de la conversación de Grice”, en M. Julio y R. Muñoz (comp.), Textos clásicos de pragmática, Madrid, Arco Libros, 1998, pp. 145174. 
Willard, Ch., "Failures of Relevance", en H. Hansen and C. Pinto (eds.), Fallacies. Classical and Contemporary Readings, Pennsylvania, The Pennsylvania State University, 1995, pp. 145-158.

Woods, J., "Sunny Prospects for Relevance?", en R. Johnson and A. Blair (eds.), New Essays in Informal Logic, Windsor, 1994, pp. 82-92.

Cristián Santibáñez Yáñez

Fecha de recepción: 3/08/2006

cristian.santibanez@udp.cl

Fecha de aceptación: 22/02/2007

Centro de estudios de la Argumentación

Facultad de Ciencias Humanas y Educación

Universidad Diego Portales

Ejército 278, Santiago, Chile 